Original Research Article

\title{
Assessment of antioxidant activity of Ocimum sanctum in healing of thermal burn wound with and without supportive treatment of silver sulfadiazine in rabbits
}

\author{
Vaibhav K. Gupta*
}

Department of Pharmacology, Shri Shankaracharya Institute of Medical Sciences, Bhilai, Chhattisgarh, India

Received: 24 April 2019 Accepted: 30 May 2019

*Correspondence to: Dr. Vaibhav K. Gupta, Email: vaibhuhotmind007@ gmail.com

Copyright: (C) the author(s), publisher and licensee Medip Academy. This is an openaccess article distributed under the terms of the Creative Commons Attribution NonCommercial License, which permits unrestricted noncommercial use, distribution, and reproduction in any medium, provided the original work is properly cited.

\begin{abstract}
Background: Burns remain a major public health issue all over the world, especially in developing countries. Pseudomonas aeruginosa is a major cause of infection and death in patients with severe burns. So, there is a need to develop drugs which will decrease complications and prevent infections more effectively than the presently used drugs.

Methods: Ocimum sanctum, ointment silver sulfadiazine and 24 Rabbits were used in this study. Animals were acclimatized and divided randomly into 04 groups of 06 animals each. After producing partial thickness burn wound ointment silver sulfadiazine was applied daily on the burn wound and Ocimum sanctum was administered orally once daily. Healing was assessed by wound contraction and Oxidative stress and Antioxidant Activity were measured by Malondialdehyde and Superoxide dismutase respectively. Results were analysed by student's 't' test, one way ANOVA followed by Dennett's test. P values $<0.05$ were considered statistically significant.

Results: At the end of treatment (After 28th Day) Group treated with ointment silver sulfadiazine+Ocimum sanctum showed maximum Percentage of wound contraction $(93.17 \pm 4.34)$, maximum decrease of MDA percentage $(0.30 \pm 0.02$ $\mathrm{nmol} / \mathrm{ml})$ and maximum increase of SOD percentage $(0.0045 \pm 0.0002 \mathrm{IU} / \mathrm{gm}$ of $\mathrm{Hb})$.

Conclusions: Most effective treatment for burn wound healing in this study was ointment silver sulfadiazine+Ocimum sanctum.
\end{abstract}

Keywords: Burn Wound healing, Ocimum sanctum, Oxidative stress, Rabbits

\section{INTRODUCTION}

According to the World Health Organization (WHO), 121 prescription medicines are produced directly from plant extracts. ${ }^{1}$

Burn can be defined as tissue damage caused by a variety of agents such as heat, chemicals, electricity, sunlight or nuclear radiation. The most common are burns caused by scalds, building fires and flammable liquids and gases. Every year, about two million people receive medical treatment for burn injury. ${ }^{2}$
Wound is defined as disruption of cellular, anatomical, and functional continuity of a living tissue. It may be produced by physical, chemical, thermal, microbial, or immunological insult to the tissue. Wound healing involves continuous cell-cell interaction and cell-matrix interactions that allow the process to proceed in different overlapping phases and processes including inflammation, wound contraction, reepithelialization, tissue remodelling, and formation of granulation tissue with angiogenesis. ${ }^{3}$ Pseudomonas aeruginosa is a major cause of infection and death or a contributing factor in the death of patients with severe burns. $^{4}$ 
Oxidative stress is defined as a state in which oxidation exceeds the antioxidant systems in the body secondary to a loss of the balance between them. ${ }^{5}$ Free radicals, reactive oxygen species (ROS) are formed during a variety of biochemical reactions and cellular functions, and act as pro-oxidants. The formation of free radicals is normally balanced by antioxidants. Oxidative stress (OS) results from an imbalance between formation and neutralization of free radicals. Oxidative stress plays an important role in edema formation after burn injury. ${ }^{6}$ A close relationship has been demonstrated between the intensity of lipid peroxidation and postburn complications, and it has been possible to document the role of ROS leading to lipid peroxidation as a causative agent in the mechanism of local and systemic complications in burns, including increased vascular permeability. ${ }^{7}$

The gold standard in topical burn treatment is Silver sulfadiazine a useful antibacterial agent for burn wound treatment. In 1968, Fox, first described the use of Silver Sulfadiazine for burn treatment, which has since become a standard antimicrobial for burn care. ${ }^{8}$ Silver Sulfadiazine (SSD) cream $1 \%$ is the most widely used topical treatment for burn injury. The antimicrobial efficacy of SSD is probably the main reason for the widespread use of this agent. ${ }^{9}$

Ocimum sanctum L. (Holy basil in English and Tulsi in Hindi), has been shown to have antioxidant properties, which may be responsible and favourable for faster wound healing. ${ }^{10}$ Higher content of linoleic acid in $O$. sanctum L. fixed oil could contribute towards its antibacterial activity. The oil show good antibacterial activity against Staphylococcus aureus, Bacillus pumius and Pseudomonas aeruginosa, where $S$. aureus was the most sensitive organism. ${ }^{11}$

So, there is a growing need to develop drugs which will decrease the complications and prevent infections more effectively than the presently used drugs. The present study was carried out to evaluate the antioxidant effect of Ocimum sanctum in healing of thermal burns and compare it with the present treatment of ointment silver sulfadiazine.

\section{METHODS}

\section{Type, place and duration of study}

This was a Preclinical Study on Rabbits conducted in the Department of Pharmacology, J. N. Medical College, Wardha and Central Research Laboratory and Central Animal House of Datta Meghe Institute of Medical Sciences (Deemed University), Wardha. Duration of study was Two years (2012-2014).

The research protocol of the study was approved by Institutional Animal Ethics Committee on 28/12/2011, vide Ref. no. DMIMSU/IAEC/2011-12/011.

\section{Procurement of plant material}

The Plant material of Ocimum sanctum (Leaves Powder) was obtained from "Rasa-shala" of Mahatma Gandhi Ayurved College, Hospital and Research Centre, Salod $(\mathrm{H})$, Wardha. This powder was ready to use for medicinal purpose.

\section{Procurement of standard drug}

Ointment silver sulfadiazine was procured from Rexcin Pharmaceuticals Private Limited, Solan, Himachal Pradesh.

\section{Procurement of anaesthetic agent}

Injection Aneket (Ketamine Hydrochloride Injection I.P.) was procured from Neon Laboratories Limited, Thane, Maharashtra State, India.

\section{Animals}

24 New Zealand White Rabbits were used in this study and were obtained from Central Animal House of Datta Meghe Institute of Medical Sciences (Deemed University), Sawangi (Meghe), Wardha.

\section{Inclusion criteria}

Rabbits of both sex (either male or female), of age group of 6-8 months and weighing $1.5 \mathrm{~kg}$ to $2 \mathrm{~kg}$ were included in this study

\section{Exclusion criteria}

Unhealthy rabbits and pregnant rabbits were excluded

\section{Acclimatization of animals}

Animals were acclimatized for 8 days in the Central Animal House before experiment. Animals were housed in separate cages under standard condition of light, temperature and humidity. They were fed with standard laboratory chow and provided with water ad libitum.

\section{Grouping of animals}

24 rabbits with age group of 6-8 month and weight 1.5 to $2 \mathrm{~kg}$ were divided randomly into 04 groups of 06 animals each (Table 1).

\section{Infliction of burn wound}

The area on the back of the rabbit is to be shaved and animal kept for fasting overnight. The next day the animal are anaesthetized using Ketamine in the dose of $50 \mathrm{mg} / \mathrm{Kg}$ of body weight I.M. ( $1 \mathrm{ml} / \mathrm{kg}$ of body weight). A metal disc of diameter $22 \mathrm{~cm}$, thickness $5 \mathrm{~mm}$ and area $380.2 \mathrm{~mm}$ square is heated in the blue portion of the flame for 5 
minute and then immediately kept on the shaved part for 30 seconds with minimal pressure (Figure 1). ${ }^{12}$

Table 1: Grouping of animals.

\begin{tabular}{|ll|}
\hline Group & No. of animals \\
\hline $\begin{array}{l}\text { Control: Not receiving any } \\
\text { treatment }\end{array}$ & 06 \\
\hline $\begin{array}{l}\text { Standard: Treated with Silver } \\
\text { Sulfadiazine }\end{array}$ & 06 \\
\hline Treated with Ocimum sanctum & 06 \\
\hline $\begin{array}{l}\text { Treated with Silver } \\
\text { Sulfadiazine+Ocimum sanctum }\end{array}$ & 06 \\
\hline
\end{tabular}

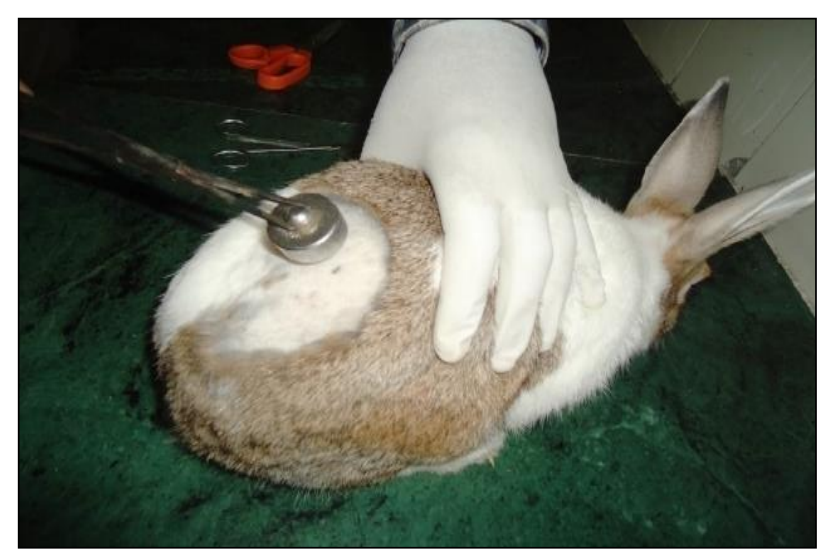

Figure 1 : Infliction of burn wound.

\section{Application of drugs}

Ointment silver sulfadiazine was applied daily on the burn wound. Ocimum sanctum was administered orally in the form of distilled water suspension in the dose of 500 $\mathrm{mg} / \mathrm{Kg}$ body weight once daily.

\section{Assessment of healing by estimation of wound contraction}

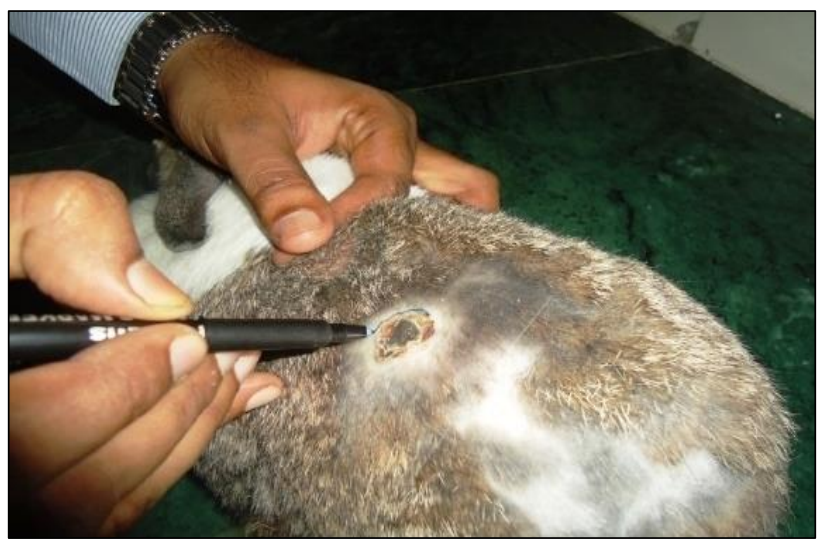

Figure 2: Measurement of wound contraction.

Wound contraction was monitored by measuring the progressive changes by tracing the raw wound area on a transparent paper on $1^{\text {st }}, 7^{\text {th }}, 14^{\text {th }}, 21^{\text {st }}$, and $28^{\text {th }}$ day of wound production. The tracing was then transferred to 1 $\mathrm{mm}^{2}$ graph sheet, from which the wound surface area was evaluated (Figure 2). ${ }^{13}$

Wound contraction $(\%)=$ Initial Wound Size- Specific Day Wound Size x 100/ Initial Wound Size

\section{Assessment of oxidative stress and antioxidant activity}

Oxidative stress injury was evaluated by measuring the level of Malondialdehyde (MDA- an end product of lipid peroxidation) and the activity of anti-oxidative enzyme Superoxide dismutase (SOD).

Malondialdehyde (MDA) and Superoxide Dismutase (SOD) were carried out spectrophotometrically on day zero (a day before the production of the burn wound) and then after 24 hours.

The subsequent readings were taken on $7^{\text {th }}, 14^{\text {th }}, 21^{\text {st }}$ and $28^{\text {th }}$ day of wound production. Both the methods were standardized in the Central Research Laboratory of Datta Meghe Institute of Medical Sciences (Deemed University), Sawangi (Meghe), Wardha. ${ }^{14,15}$

\section{Statistical analysis}

Results were reported as mean $\pm \mathrm{SD}$. The data were analyzed by student's ' $t$ ' test, one way ANOVA followed by Dennett's test. $\mathrm{P}$ values $<0.05$ were considered statistically significant.

\section{RESULTS}

Wound contraction was measured on $1^{\text {st }}, 7^{\text {th }}, 14^{\text {th }}, 21^{\text {st }}$ and $28^{\text {th }}$ day of wound production and expressed in the form of percentage of wound contraction (Table 2).

At the end of treatment (After $28^{\text {th }}$ Day) Percentage of wound contraction was maximum $(93.17 \pm 4.34)$ was in group treated with ointment silver sulfadiazine+Ocimum sanctum.

Oxidative stress injury was evaluated by measuring the level of Malondialdehyde (MDA)-an end product of lipid peroxidation. MDA was measured on day 0 (a day before the production of the burn wound), $1^{\text {st }}, 7^{\text {th }}, 14^{\text {th }}, 21^{\text {st }}$ and $28^{\text {th }}$ day of wound production. Malondialdehyde (MDA) was expressed in $\mathrm{nmol} / \mathrm{ml}$ (Table 3).

Oxidative stress injury was evaluated by measuring the activity of anti-oxidative enzyme such as Superoxide Dismutase (SOD).

Superoxide Dismutase (SOD) was measured on day 0 (a day before the production of the burn wound), $1^{\text {st }}, 7^{\text {th }}, 14^{\text {th }}$, $21^{\text {st }}$ and $28^{\text {th }}$ day of wound production. SOD level is expressed in IU/gm of $\mathrm{Hb}$ (Table 4). 
Table 2: Percentage of wound contraction.

\begin{tabular}{|c|c|c|c|c|c|}
\hline \multirow{2}{*}{ Group } & \multicolumn{5}{|c|}{ Percentage of wound contraction (Mean \pm SD) } \\
\hline & Day 1 & Day 7 & Day 14 & Day 21 & Day 28 \\
\hline Control & $0 \pm 0$ & $20.63 \pm 2.67$ & $35.23 \pm 2.55$ & $49.53 \pm 4.19$ & $60.37 \pm 5.44$ \\
\hline Standard & $0 \pm 0$ & $21.17 \pm 5.13$ & $38.17 \pm 8.58$ & $55.62 \pm 4.07$ & $72 \pm 3.66$ \\
\hline Os & $0 \pm 0$ & $14.17 \pm 4.11$ & $30.62 \pm 6.15$ & $50.10 \pm 3.39$ & $65.18 \pm 2.37$ \\
\hline $\mathrm{SS}+\mathrm{Os}$ & $0 \pm 0$ & $41.75 \pm 9.00$ & $73.37 \pm 8.51$ & $87.07 \pm 4.81$ & $93.17 \pm 4.34$ \\
\hline \multicolumn{6}{|c|}{ Comparison of percentage of wound contraction at $28^{\text {th }}$ day (by one-way anova and dunnett's test) } \\
\hline & Mean Difference & Standard Error & P value & \multicolumn{2}{|c|}{$\begin{array}{l}\text { Level of significance (As compared to control } \\
\text { group) }\end{array}$} \\
\hline Standard & 11.63 & 2.41 & 0.000 & \multicolumn{2}{|c|}{$\mathrm{P}<0.05$ Significant } \\
\hline Os & 4.81 & 2.41 & 0.234 & \multicolumn{2}{|c|}{$\mathrm{P}>0.05 \quad$ Not significant } \\
\hline $\mathrm{SS}+\mathrm{Os}$ & 32.80 & 2.41 & 0.000 & \multicolumn{2}{|c|}{$\mathrm{P}<0.05 \quad$ Significant } \\
\hline
\end{tabular}

Table 3: Estimation of MDA.

\begin{tabular}{|c|c|c|c|c|c|}
\hline \multirow{2}{*}{ Group } & \multicolumn{5}{|c|}{ MDA (In nmol/ml) (Mean \pm SD) } \\
\hline & Day 1 & Day 7 & Day 14 & Day 21 & Day 28 \\
\hline Control & $0.27 \pm 0.02$ & $0.42 \pm 0.02$ & $0.41 \pm 0.02$ & $0.40 \pm 0.02$ & $0.40 \pm 0.02$ \\
\hline Standard & $0.29 \pm 0.01$ & $0.46 \pm 0.01$ & $0.43 \pm 0.01$ & $0.41 \pm 0.02$ & $0.40 \pm 0.02$ \\
\hline Os & $0.27 \pm 0.01$ & $0.42 \pm 0.01$ & $0.39 \pm 0.02$ & $0.38 \pm 0.02$ & $0.37 \pm 0.02$ \\
\hline \multirow[t]{3}{*}{$\mathrm{SS}+\mathrm{Os}$} & $0.28 \pm 0.02$ & $0.44 \pm 0.03$ & $0.40 \pm 0.02$ & $0.35 \pm 0.02$ & $0.30 \pm 0.02$ \\
\hline & \multicolumn{5}{|c|}{ Comparison of MDA level in different groups at $28^{\text {th }}$ day (by one way anova and dunnett's test) } \\
\hline & Mean difference & Standard error & P value & $\begin{array}{l}\text { Level of si } \\
\text { group) }\end{array}$ & ignificance (as compared to control \\
\hline Standard & -0.0008 & 0.009 & 1.000 & $\mathrm{P}>0.05$ & Not significant \\
\hline Os & -0.03 & 0.009 & 0.116 & $\mathrm{P}<0.05$ & Not significant \\
\hline SS+Os & -0.13 & 0.009 & 0.000 & $\mathrm{P}<0.05$ & Significant \\
\hline
\end{tabular}

Table 4: Estimation of SOD.

\begin{tabular}{|c|c|c|c|c|c|}
\hline \multirow{2}{*}{ Group } & \multicolumn{5}{|c|}{ SOD (In IU/gm of Hb) (Mean \pm SD) } \\
\hline & Day 1 & Day 7 & Day 14 & Day 21 & Day 28 \\
\hline Control & $0.0048 \pm 0.0005$ & $0.0036 \pm 0.0004$ & $0.0037 \pm 0.0004$ & $0.0037 \pm 0.0004$ & $0.0038 \pm 0.0004$ \\
\hline Standard & $0.0050 \pm 0.0006$ & $0.0038 \pm 0.0004$ & $0.0039 \pm 0.0004$ & $0.0040 \pm 0.0005$ & $0.0041 \pm 0.0004$ \\
\hline Os & $0.0047 \pm 0.0005$ & $0.0036 \pm 0.0005$ & $0.0036 \pm 0.0005$ & $0.0036 \pm 0.0005$ & $0.0037 \pm 0.0005$ \\
\hline \multirow[t]{3}{*}{$\mathrm{SS}+\mathrm{Os}$} & $0.0049 \pm 0.0001$ & $0.0038 \pm 0.0002$ & $0.0040 \pm 0.0002$ & $0.0043 \pm 0.0002$ & $0.0045 \pm 0.0002$ \\
\hline & \multicolumn{5}{|c|}{ Comparison of sod level in different groups at $28^{\text {th }}$ day (by one way anova and dunnett's test) } \\
\hline & Mean Difference & Standard Error & P value & \multicolumn{2}{|c|}{$\begin{array}{l}\text { Level of significance (as compared to } \\
\text { control group) }\end{array}$} \\
\hline Standard & 0.0002 & 0.0002 & 0.419 & $\mathrm{P}>0.05$ & cant \\
\hline Os & 0.00003 & 0.0002 & 1.000 & $\mathrm{P}>0.05$ & cant \\
\hline $\mathrm{SS}+\mathrm{Os}$ & 0.0009 & 0.0002 & 0.000 & $\mathrm{P}<0.05$ & \\
\hline
\end{tabular}

\section{DISCUSSION}

Thermal injury of the skin is an oxidation process associated with biological and metabolic alterations. It generates free radicals from various cellular populations by a number of pathways and the modulation of generated free radical activity with antioxidants may improve outcome. ${ }^{7}$ Oxidative stress is the shift in ratio between oxidants and antioxidants either due to excessive reactive oxygen species (ROS) generation and/or decrease in antioxidant defences. ${ }^{16}$ Oxidative stress injury was evaluated by measuring the levels of Malondialdehyde (MDA- an end product of lipid peroxidation), and the activity of anti-oxidative enzymes such as Superoxide Dismutase (SOD). Malondialdehyde (MDA) is the most abundant aldehyde resulting from lipid peroxidation. Superoxide dismutase (SOD) is one of the most important of antioxidant enzymes. It catalyses dismutation of superoxide radicals to hydrogen peroxide and molecular oxygen. It acts with a rate of 10,000 times faster than the 
spontaneous rate of superoxide radical dismutation. ${ }^{16}$ Maximum decrease of MDA percentage after complete treatment was found in Group treated with ointment silver sulfadiazine+Ocimum sanctum. Maximum increase of SOD percentage after complete treatment was found in following Group treated with ointment silver sulfadiazine+Ocimum sanctum. Study conducted by Hossenimehr SJ et al, on effect of aloe cream versus silver sulfadiazine for healing burn wounds in rats, reported that the antimicrobial effect is the major mechanism of silver sulfadiazine in wound healing. ${ }^{9}$ The silver ion binds to the organism DNA and consequently releases the sulphonamides that kill the microbes. Study conducted by Asha B et al, on Study of wound healing activity of topical Ocimum sanctum Linn in albino rats reported that flavonoids responsible for the free radical scavenging activity that is believed to be one of the most important components of wound healing. ${ }^{17}$ Another study conducted by Devendran $\mathrm{G}$ et al, on Qualitative phytochemical screening and GC-MS analysis of Ocimum sanctum L. leaves reported that the presence of eugenol attributes to its antioxidative property and is also thought to be responsible for inhibition of lipid peroxidation. ${ }^{18}$

\section{CONCLUSION}

Group treated with standard drug ointment silver sulfadiazine+Ocimum sanctum was found effective in healing of burn wound because this combination significantly increased the percentage of wound contraction and significantly decreased the oxidative stress. So, the most effective treatment for burn wound healing in this study was ointment silver sulfadiazine+Ocimum sanctum.

Funding: No funding sources

Conflict of interest: None declared

Ethical approval: The study was approved by the Institutional Animal Ethics Committee (vide Ref. no. DMIMSU/IAEC/2011-12/011)

\section{REFERENCES}

1. Pradhan SL, Pradhan PS. Ayurvedic medicine and anaesthesia. Indian J Anaesth. 2011;55(4):334-9.

2. Shrivastava P, Durgaprasad S. Burn wound healing property of Cocos nucifera : An Appraisal. Indian J Pharmacol. 2008;40(4):144-6.

3. Gupta VK, Chandraker S, Keche YN, Ingole N. Preclinical evaluation of burn wound healing property of Ocimum sanctum in rabbits-A histopathological study. Int J Pharm Phytopharmacol Res. 2015;5(3):226.

4. Sutter VL, Hurst V. Sources of pseudomonas aeruginosa infection in burns: study of wound and rectal cultures with phage typing. Ann Surg. 1966;163(4):597-602.

5. Yoshikawa T, Naito Y. What is oxidative stress? Japan Med Assoc J. 2002;45(7):271-6.
6. Mühl D, Woth G, Drenkovics L, Varga A, Ghosh S, Csontos C, et al. Comparison of oxidative stress and leukocyte activation in patients with severe sepsis and burn injury. Indian J Med Res. 2011;134(1):69-78.

7. Sahib AS, Al-Jawad FH, Al-Kaisy AA. Burns, endothelial dysfunction, and oxidative stress: the role of antioxidants. ann burns fire disasters. 2009;22(1):611.

8. Borsuk DE, Gallant M, Richard D, Williams HB. Silver-coated nylon dressings for pediatric burn victims. Can J of Plast Surg. 2007;15(1): 29-31.

9. Hosseinimehr SJ, Khorasani G, Azadbakht M, Zamani P, Ghasemi M, Ahmadi A. effect of aloe cream versus silver sulfadiazine for healing burn wounds in rats. Acta Dermatovenerol Croat. 2010;18(1):2-7.

10. Goel A, Kumar S, Singh DK, Bhatia AK. Wound healing potential of Ocimum sanctum Linn. with induction of tumor necrosis factor- $\alpha$. Indian $J$ Exp Biol. 2010;48(4):402-6.

11. Pattanayak P, Behera P, Das D, Panda SK. Ocimum sanctum Linn. A reservoir plant for therapeutic applications: An overview. Phcog Rev. 2010;4(7):95105.

12. Gupta VK, Pathak SS, Jain MK. Evaluation of burn wound healing property of Ocimum sanctum by monitoring of period of reepithelization in rabbits. Int J Basic Clin Pharmacol. 2016;5(1):146-8.

13. Gupta VK, Pathak SS. Preclinical evaluation of wound contraction property of Ocimum sanctum with and without supportive treatment of silver sulfadiazine in Rabbits. J Pharmacogn Phytochem. 2016;5(2):96-8.

14. Ohkawa H, Ohishi N, Yagi K. Assay for lipid peroxides in animal tissues by thiobarbituric acid reaction. Anal Biochem. 1979;95(2):351-8.

15. Marklund S, Marklund G. involvement of superoxide anion radical in the autoxidation of pyrogallol and a convenient assay for superoxide dismutase. Eur $\mathbf{J}$ Biochem. 1974; 47:469-74.

16. Tosson Z, Mokadem SA, Attwa E, Nofal I, Sayed MME, Gaber OA. The relation of Malondialdehyde and Superoxide Dismutse to the pathogenesis of Systemic Lupus Erythematosus and Effect of Antioxidants on the disease activity. Egypt Dermat Online J. 2006;2(2):10.

17. Asha B, Nagabhushan A, Shashikala GH. Study of wound healing activity of topical Ocimum sanctum Linn in albino rats. J Chem Pharm Res. 2011;3(6):1226.

18. Devendran G, Balasubramanian U. Qualitative Phytochemical Screening and GC-MS analysis of Ocimum sanctum L. leaves. Asian J Plant Sci Res. 2011;1(4):44-8.

Cite this article as: Gupta VK. Assessment of antioxidant activity of Ocimum sanctum in healing of thermal burn wound with and without supportive treatment of silver sulfadiazine in rabbits. Int J Basic Clin Pharmacol 2019;8:1594-8. 